\title{
Determinação de minerais no solo e análise de folhas de couve produzida em Brasília
}

\author{
Determination of soil mineral content and analysis of collards leaves grown in Brasília
}

\author{
Rita de Fátima Alves Luengo1*, Nicole-Marie dos Santos Butruille ${ }^{2}$, Raphael Augusto de Castro e Melo1, \\ Juscimar da Silva1, Iriani Rodrigues Maldonade', Antônio Dantas Costa Júnior ${ }^{3}$
}

${ }^{1}$ Empresa Brasileira de Pesquisa Agropecuária (EMBRAPA), Centro Nacional de Pesquisas de Hortaliças, Brasília/DF - Brasil

Universidade de Brasília (UnB), Brasília/DF - Brasil

${ }^{3}$ Empresa de Assistência Técnica e Extensão Rural do Distrito Federal (EMATER-DF), Brasília/DF - Brasil

\section{${ }^{*}$ Corresponding Author}

Rita de Fátima Alves Luengo, Empresa Brasileira de Pesquisa Agropecuária (EMBRAPA), Centro Nacional de Pesquisas em Hortaliças, Rodovia BR 060, km 09, Caixa Postal: 218, CEP: 70275-970, Brasília/DF - Brasil, e-mail: rita.luengo@embrapa.br

Cite as: Determination of soil mineral content and analyses of collards leaves grown in Brasília. Braz. J. Food Technol., v. 21, e2017141, 2018.

Received: Sept. 04, 2017; Accepted: Dec. 13, 2017

\section{Resumo}

A couve de folhas é um alimento com alto teor de vitaminas e minerais, que são fundamentais para a dieta humana. Contudo, informações sobre a influência dos fatores extrínsecos e intrínsecos, durante o seu cultivo, em sua composição são escassas. O objetivo deste trabalho foi quantificar os seguintes minerais em folhas de couves produzidas no Distrito Federal (DF): cálcio, magnésio, potássio, fósforo, zinco, manganês, sódio e ferro, correlacionando os teores verificados com os teores presentes no solo. As amostras de folhas e solo foram coletadas em 16 diferentes propriedades rurais no DF, quando também foram aplicados questionários aos produtores sobre as práticas culturais adotadas durante a produção. Os resultados obtidos de teores médios foliares (base em folhas frescas) por $100 \mathrm{~g}$ de alimento foram: cálcio, 222,8 mg; ferro, 1,3 mg; magnésio, 37,6 mg, e zinco, 0,6 mg. Esta composição atende a 28\% das necessidades diárias de cálcio em crianças de 4 a 8 anos, sendo também supridos 13\% de ferro, 29\% de magnésio e 13\% de zinco, com base no consumo de $100 \mathrm{~g}$ de folhas frescas de couve. Foi verificada correlação negativa para teores de magnésio no solo e na folha, com $R=-0,69$. Para os outros minerais analisados não se verificou correlação significativa. O conteúdo de fósforo e de potássio nos solos foi considerado alto, enquanto que, contrariamente, foram determinadas concentrações baixas de teores de magnésio. O teor de micronutrientes na couve foi considerado baixo e aventa para um manejo inadequado da adubação, fator corroborado pelas respostas dos questionários sobre práticas culturais. Práticas de manejo que levam ao equilíbrio de nutrientes no solo refletem diretamente na interação solo-planta. Recomendações regionais atualizadas de adubação e correção dos solos poderiam auxiliar agricultores e técnicos, refletindo diretamente na obtenção de teores mais equilibrados de micro e macronutrientes em alimentos de origem vegetal.

Palavras-chave: Brassica oleracea var. acephala; Adubação; Composição nutricional.

\section{Abstract}

Collard is a food with a high content of vitamins and minerals, fundamental for the human diet. However, information on the influence of extrinsic and intrinsic factors in its composition during cultivation is still scarce. The objective of this work was to quantify the minerals in collard leaves produced in the Federal District (DF), Brazil: calcium, magnesium, potassium, phosphorus, zinc, manganese, sodium and iron, correlating with the present soil contents. Leaf and soil samples were collected in 16 different rural properties in the Federal District, in which questionnaires were also applied on the cultural practices adopted during plant growing. The average foliar contents per $100 \mathrm{~g}$ of fresh leaves were: calcium, $222.8 \mathrm{mg}$; iron, $1.3 \mathrm{mg}$; magnesium, $37.6 \mathrm{mg}$; and zinc, $0.6 \mathrm{mg}$. This composition meets $28 \%$ of daily calcium requirements in children aged from 4 to 8 years: $13 \%$ iron, $29 \%$ magnesium and $13 \%$ zinc, based on the consumption of $100 \mathrm{~g}$ of fresh collard leaves. Negative correlation was verified for magnesium contents in soil and leaf, with $R=-0.69$. A significant correlation was not verified for the other analyzed minerals. Phosphorus and potassium contents in soils were considered high while, contradictorily, low 
concentrations of magnesium were found. The foliar micronutrients contents were considered low and suggests for an inadequate management of the fertilization, factor corroborated by the answers of the cultural practices questionnaires. Management practices that lead to nutrient balance in soil reflect directly on soil-plant interaction. Up-to-date regional recommendations on soil fertilization and correction could assist farmers and technicians, directly reflecting the achievement of more balanced levels of micro and macro nutrients in vegetables.

Keywords: Brassica oleracea var. acephala; Soil fertilization; Nutritional composition.

\section{Introdução}

Os minerais são importantes tanto para processos metabólicos da planta quanto para seres humanos. Nas plantas, o magnésio está no centro da molécula de clorofila e é o intermediário para a produção de carboidratos. O cálcio é responsável pela rigidez da parede celular. O ferro não faz parte da clorofila, mas é necessário para que esta se forme; participa também da fotossíntese, do desenvolvimento dos cloroplastos e do desenvolvimento dos ribossomos. O zinco é importante para o metabolismo da planta e sua deficiência pode levar ao acúmulo de outros nutrientes, inclusive o fósforo, tornando-os incapazes de formar substâncias orgânicas. Sua deficiência pode provocar toxidez de fósforo (PRIMAVESI, 2002). Para os humanos, os minerais são nutrientes importantes e são obtidos principalmente por meio da alimentação. Entre os minerais, o cálcio $(\mathrm{Ca})$ é importante na manutenção óssea, na prevenção da osteoporose e no controle da pressão arterial; o magnésio $(\mathrm{Mg})$ é fundamental para a fixação do cálcio no organismo; o ferro (Fe) e as vitaminas A e C são importantes para sanar anemias crônicas (BRASIL, 2002). Estas doenças são muito comuns na população brasileira, sendo a anemia ferropriva o principal tipo, diagnosticada em 95\% dos casos. Os valores dos compostos nutricionais de couves têm sido obtidos por diversas instituições (LUENGO et al., 2000; UNICAMP, 2006; UNIFESP, 2016); no entanto, desconsideram-se diferentes fatores que podem causar variações, como o ambiente de cultivo do produto, os sistemas de produção e as variedades cultivadas, podendo haver genótipos com quantidades de compostos nutricionais diferentes dentro da mesma espécie vegetal. Alimentos ricos em cálcio são principalmente o leite e derivados, e vegetais folhosos de cor verde escura (BUENO; CZEPIELEWSKI, 2008). O magnésio, presente em grande quantidade nos vegetais verdes e especialmente nos verde-escuros, é fundamental para a fixação do cálcio no organismo (VAN DER SLUIS; MUINCK KEIZER-SCHRAMA, 2001). O zinco pode ajudar a atenuar os efeitos do estresse do ponto de vista nutricional (MENDES, 1988) e tem importante papel durante a fase de crescimento de crianças e adolescentes (SALGUEIRO et al., 2002). De acordo com Fadigas et al. (2010), a couve é rica em todos esses elementos e comumente utilizada em programas alimentares (dietas).

O objetivo deste trabalho foi quantificar os seguintes minerais, em folhas de couve de diferentes genótipos, produzida no Distrito Federal: cálcio, magnésio, potássio, fósforo, zinco, manganês, sódio e ferro, correlacionando os teores verificados com os teores destes minerais presentes nos solos onde foram cultivadas, além de comparar os dados obtidos com os dados da literatura existente.

\section{Material e métodos}

As amostras de folhas de couve foram coletadas em 16 propriedades do DF, em locais onde a produção é representativa, tendo sido auxiliada pela EMATER-DF (Empresa de Assistência Técnica e Extensão Rural do Distrito Federal), com base no sistema SisAter (Sistema de Assistência Técnica e Extensão Rural), que é um banco de dados referente ao cadastro de produtores e que quantifica as ações de assistência técnica e extensão que a empresa desempenha na área rural (SOARES, 2013). As folhas colhidas para amostras foram a terceira ou a quarta folha da planta, no sentido do ápice da planta para as raízes (TRANI et al., 2015), desenvolvidas completamente, considerando que as colheitas são regulares e frequentes durante a semana, dependendo do local de comercialização. Foram colhidas 40 folhas de 40 plantas por gleba homogênea. Para uma amostra composta de solo, foram coletados 20 pontos/ha na profundidade de $0 \mathrm{~cm}$ a $20 \mathrm{~cm}$. No Brasil, a couve tem sido classificada pela diversidade de aparência, cor e textura da folha. As couves do tipo manteiga, denominação que se refere à maciez da folha ao tato e ao tempo de preparo culinário, incluem tanto variedades de folhas de cor verde-clara quanto de coloração verde-escura (TRANI et al., 2015). As couves do tipo manteiga são propagadas vegetativamente e representam quase que a totalidade da área cultivada no país, não diferindo das condições do presente estudo. As couves cultivadas são assim denominadas pelos produtores do DF, não sendo possível diferenciá-las sem um estudo específico - morfológico ou molecular.

As folhas de couve foram lavadas com água destilada e colocadas em embalagens de papel, para secar em estufa de circulação forçada de ar, à temperatura de aproximadamente $60^{\circ} \mathrm{C}$, até massa constante. Depois de secas, as amostras foram trituradas com auxílio de moinho de facas do tipo Willey. Depois de moídas, as amostras foram submetidas à solubilização ácida em ambiente fechado, utilizando forno micro-ondas da Marca CEM, modelo Mars Xpress. Para tanto, 0,5000 g de material vegetal foi pesado, acondicionado em tubos de Teflon ${ }^{\circledast}$, 
específicos para o forno de micro-ondas, juntamente com $9 \mathrm{~mL}$ do ácido nítrico e $3 \mathrm{~mL}$ de peróxido de hidrogênio. As condições operacionais do forno de micro-ondas utilizado foram: potência do forno $=800 \mathrm{~W}$; tempo total de reação = 22 min; Estagio 1 (temperatura $100^{\circ} \mathrm{C}$ ): tempo de rampa $($ Ramp $)=5$ min, tempo necessário para atingir a temperatura estabelecida; tempo de solubilização (hold) $=10 \mathrm{~min}$; Estagio 2 (temperatura $180^{\circ} \mathrm{C}$ ): tempo de rampa $($ Ramp) $=2$ min; tempo de solubilização (hold) $=5 \mathrm{~min}$.

Após o período de reação, aguardou-se o tempo necessário para o equilíbrio térmico dos tubos à temperatura ambiente. Em seguida, os tubos foram abertos em capela com exaustão de gases e os extratos filtrados para balões de vidro com capacidade para $50 \mathrm{~mL}$, os quais tiveram seu volume completado com água padrão ultrapuro (Milli-Q element,

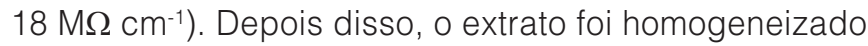
e transferido para frasco plástico previamente limpo, com capacidade para $50 \mathrm{~mL}$, e armazenado em refrigerador a $4{ }^{\circ} \mathrm{C}$, para posterior análise. Para verificar a recuperação do método analítico, foram utilizadas duas amostras de referência padrão (NIST SRM 1570a - spinach leaves e $1573 a$ - tomato leaves). A recuperação foi considerada adequada e variou de $92 \%$ a $110 \%$. O ensaio foi realizado em triplicata e todos os reagentes químicos utilizados foram de alto grau analítico.

A determinação dos teores de minerais nos diferentes extratos foi efetuada em espectrômetro de emissão atômica com fonte de indução de plasma acoplada (ICP/OES) marca Shimadzu modelo ICPE-9000. O aparelho foi ligado para o aquecimento da fonte de plasma por, no mínimo, 30 minutos antes do início da série de análises. As condições operacionais do ICP-OES, bem como os comprimentos de onda utilizados para cada elemento, estão na Tabela 1.

As amostras representativas de solo foram retiradas na profundidade de $0 \mathrm{~cm}$ a $20 \mathrm{~cm}$, porção equivalente para a maioria dos solos ao horizonte A. O solo foi coletado com trado tipo caneco, fabricado em aço inox, com capacidade de $0,750 \mathrm{dm}^{3}$ e $16 \mathrm{~cm}$ de altura. Depois de coletado, o solo foi armazenado em sacos plásticos, etiquetado e transportado até o Laboratório de Solos e Nutrição de Plantas da Embrapa Hortaliças.

Nas dependências do Laboratório da Embrapa, o solo foi retirado dos sacos plásticos e seco à sombra. Cuidados foram tomados para evitar possíveis contaminações cruzadas, principalmente com material particulado (ex.: poeira). Depois de secas, as amostras foram peneiradas em peneira aço inox com malha de dois milímetros, constituindo a terra fina seca ao ar (TFSA). Depois de peneiradas, as amostras foram armazenadas em frascos plásticos. Subamostras de aproximadamente $50 \mathrm{~g}$ de TFSA foram utilizadas para realização das análises de caracterização química e para fins de caracterização de sua fertilidade. As análises químicas realizadas foram
pH em água, capacidade de troca de cátions, $\mathrm{Ca}^{2+}, \mathrm{Mg}^{2+}$, $\mathrm{Al}^{3+}$ trocáveis, $\mathrm{P}$ e K disponíveis, matéria orgânica do solo, acidez ativa e acidez potencial (SILVA, 2009).

Os teores foliares encontrados, em termos de necessidade de ingestão diária, foram transformados e comparados à tabela nutricional da USDA (OTTEN et al., 2006), e, para análise de nutrição mineral, comparados às faixas adequadas propostas por Trani et al. (2015).

\section{Resultados e discussão}

A média dos valores encontrados nos solos para os conteúdos de macro e micronutrientes é apresentada na Tabela 2, com os respectivos desvios-padrão, evidenciando grande variabilidade entre os solos. Tomando-se como referência as recomendações para o uso de corretivos, matéria orgânica e fertilizantes para hortaliças no Distrito Federal (EMATER-DF, 1987), o conteúdo de fósforo foi considerado muito alto (> $60 \mathrm{mg} / \mathrm{dm}^{3}$ ) em $71 \%$ das propriedades, e o de potássio, em 93\% delas (> $240 \mathrm{mg} / \mathrm{dm}^{3}$ ). Valores considerados altos para fósforo podem ser decorrentes

Tabela 1. Condições operacionais do espectrômetro de emissão atômica com fonte de indução de plasma acoplada (ICP/OES) para determinação de minerais em couve.

\begin{tabular}{|c|c|}
\hline Instrumento & $\begin{array}{l}\text { Condição } \\
\text { operacional }\end{array}$ \\
\hline \multicolumn{2}{|l|}{ ICP-OES } \\
\hline \multicolumn{2}{|l|}{ Shimadzu, modelo ICPE 9000} \\
\hline Potência de radiofrequência (W) & 1.300 \\
\hline Plano de visão & Axial \\
\hline Plasma (L min $\left.{ }^{-1}\right)$ & 10,0 \\
\hline Nebulizador $\left(\mathrm{L} \mathrm{min}^{-1}\right)$ & 0,8 \\
\hline Gás auxiliar ( $\left(\mathrm{min}^{-1}\right)$ & 0,7 \\
\hline Tempo de integração (s) & 5,0 \\
\hline Retardamento da leitura (s) & 45,0 \\
\hline $\begin{array}{l}\text { Vasão da bomba peristáltica } \\
\left(\mathrm{mL} \min ^{-1}\right)\end{array}$ & 1,5 \\
\hline Repetição das leituras & 3,0 \\
\hline $\begin{array}{l}\text { Comprimentos de onda } \\
\text { utilizados }(\eta m)\end{array}$ & $\begin{array}{c}\text { B, 249.677; Cu, } \\
\text { 324.752; Fe, 259.959; } \\
\text { Hg, 253.652; Mn, } \\
\text { 267.610; Ni, 231.604; } \\
\text { Zn, 213.857. }\end{array}$ \\
\hline
\end{tabular}

Tabela 2. Teores médios de minerais em solo de cultivo de couve no DF.

\begin{tabular}{|c|c|c|c|}
\hline $\mathbf{P}$ & K & $\mathrm{Ca}$ & Mg \\
\hline \multicolumn{2}{|c|}{$\mathrm{mg} \mathrm{dm}^{-3}$} & \multicolumn{2}{|c|}{$\mathrm{cmol}_{\mathrm{c}} \mathrm{dm}^{-3}$} \\
\hline $750,91 \pm 434,45$ & $405,78 \pm 139,55$ & $4,79 \pm 2,38$ & $1,39 \pm 0,64$ \\
\hline $\mathrm{Zn}$ & Mn & $\mathrm{Na}$ & $\mathrm{Fe}$ \\
\hline \multicolumn{4}{|c|}{$\mathrm{mg} \mathrm{dm}^{-3}$} \\
\hline ,45 & 3,03 & 50,0 & 70 \\
\hline
\end{tabular}


Determinação de minerais no solo e análise de folhas de couve produzida em Brasília

Luengo, R. F. A. et al.

da metodologia de análise. Para determinação dos teores disponíveis de $\mathrm{P}$, em solos tropicais utiliza-se o extrator duplo ácido $\left(\mathrm{HCl} 0,05 \mathrm{~mol} \mathrm{~L}^{-1}+\mathrm{H}_{2} \mathrm{SO}_{4} 0,025 \mathrm{~mol} \mathrm{~L}^{-1}\right)$, Mehlich 1. O uso de fosfatos de rocha, como fonte de fertilizante fosfatado, é muito comum em áreas olerícolas; assim, é bem provável que, durante a análise, partículas residuais da rocha fosfatada presentes no solo tenham sido solubilizadas, dado o caráter ácido do extrator, explicando-se, dessa forma, os altos teores observados. Em solos adubados, é de se esperar que a reserva de fósforo lábil se encontre, em grande parte, na forma de fosfatos de alumínio, principalmente, se os solos forem ácidos. Torna-se preferível, então, o uso de extratores ou métodos que tenham maior ação sobre esta fração, como é o caso dos métodos Bray e Resina e do método Olsen (RAIJ et al., 1984 apud BRAGA et al., 2010). Por outro lado, foram constatados valores médios e baixos de magnésio em $43 \%$ dos solos analisados $\left(<0,5 \mathrm{cmol}_{\mathrm{c}} / \mathrm{dm}^{3}\right.$ baixo e entre 0,6 e 1,0 $\mathrm{cmol}_{\mathrm{c}} / \mathrm{dm}^{3}$ médio) (Figura 1).

A análise foliar evidenciou que há deficiência de alguns elementos (Figura 2), por meio de fertigramas, que são gráficos construídos com círculos concêntricos, com tantas divisões radiais quantos forem os elementos a serem plotados. Na interseção entre o círculo mediano e os segmentos radiais, são alocados os valores dos níveis críticos determinados previamente para a cultura em questão (MARTINEZ et al., 1999). As concentrações obtidas das análises foliares de determinada lavoura são então plotadas no fertigrama, no raio correspondente, e, após a ligação dos pontos, origina-se um polígono, a partir do qual se interpreta o estado nutricional da cultura. Picos a partir do círculo de níveis críticos indicam excessos e reentrâncias significam deficiência (MARTINEZ et al., 1999). Tomando-se como referência a faixa de teores adequados proposta por Trani et al. (2015) (Tabela 3), os teores foliares de magnésio estão abaixo do nível crítico em $61 \%$ das propriedades, assim como os teores de boro, em $83 \%$, e os teores de manganês, em 78\% (Tabela 4).

Verificouse correlação negativa entre os teores de Mg no solo e na folha, com $\mathrm{R}=-0,69$ (Figura 3). Para os demais minerais analisados, não houve correlação significativa. Possíveis explicações para o fato são a
A

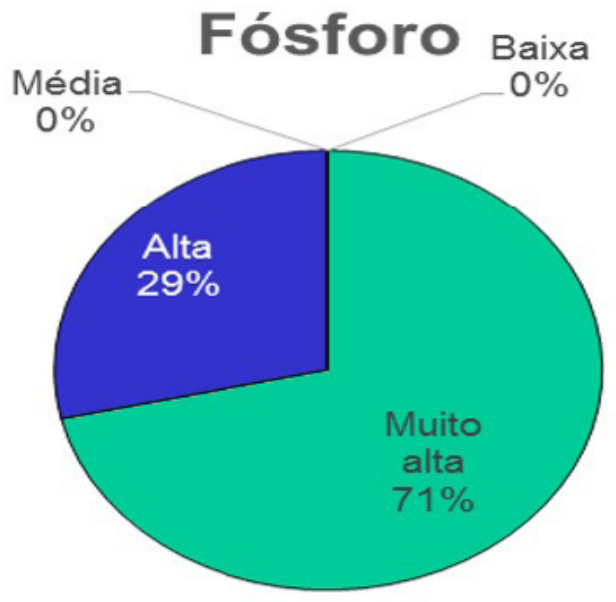

Magnésio

C

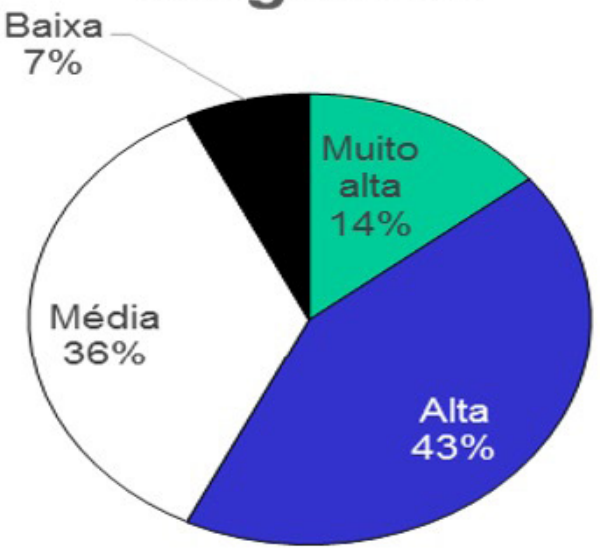

B

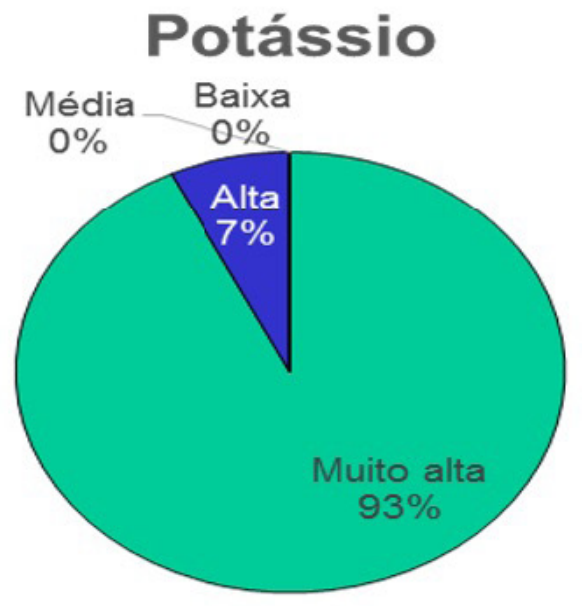

\section{Cálcio}

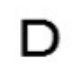

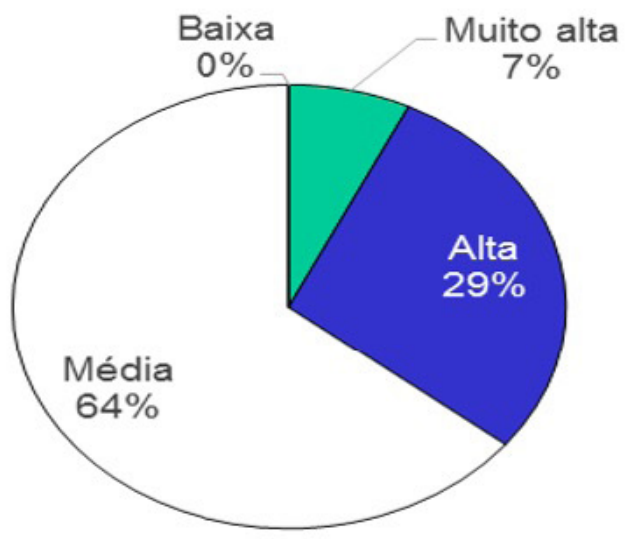

Figura 1. Classes de fertilidade dos solos sob cultivo de couve no DF. As letras de identificação A a D indicam respectivamente fósforo, potássio, magnésio e cálcio. 
A

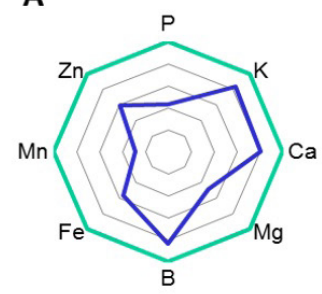

E

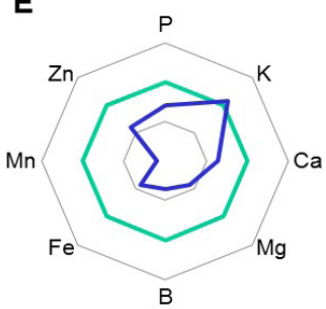

I

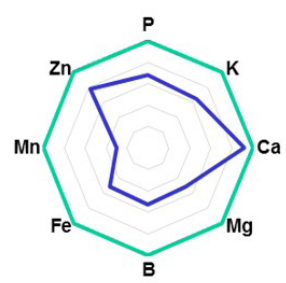

M

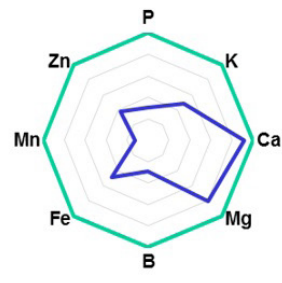

B

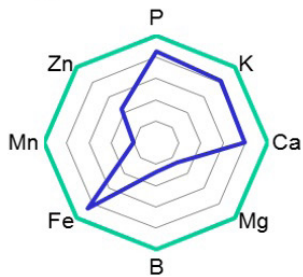

$\mathbf{F}$
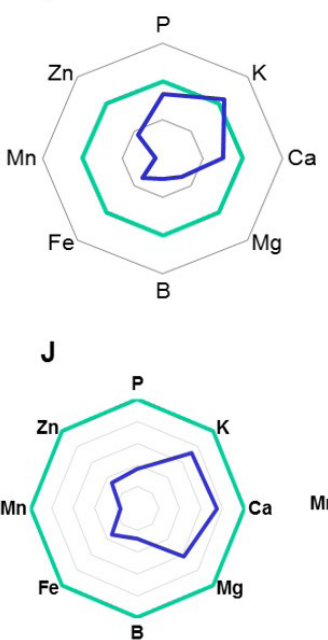

N

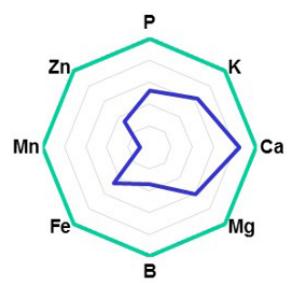

C

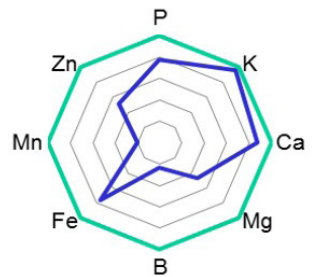

G

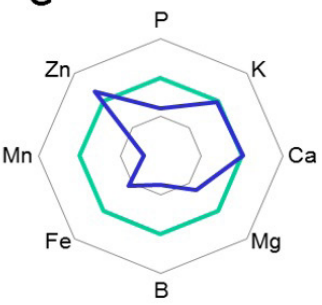

D

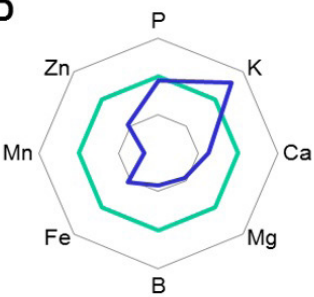

H

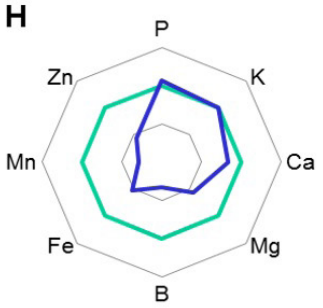

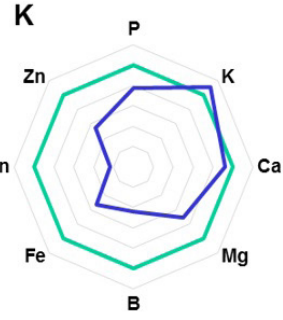

0

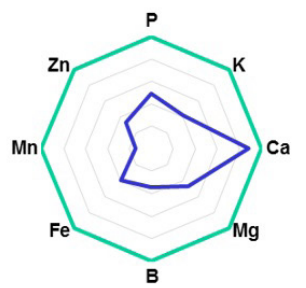

L

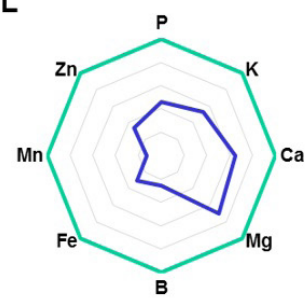

$\mathbf{P}$

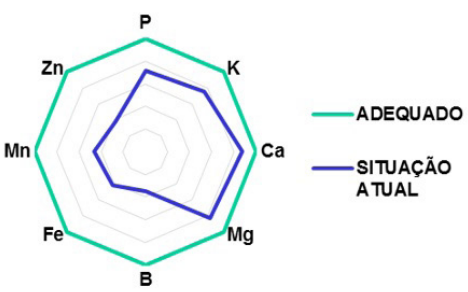

Letras em maiúsculo representam cada propriedade analisada.

Figura 2. Fertigramas de teores foliares dos minerais em couve. As letras de A até P indicam dados de amostras diferentes.

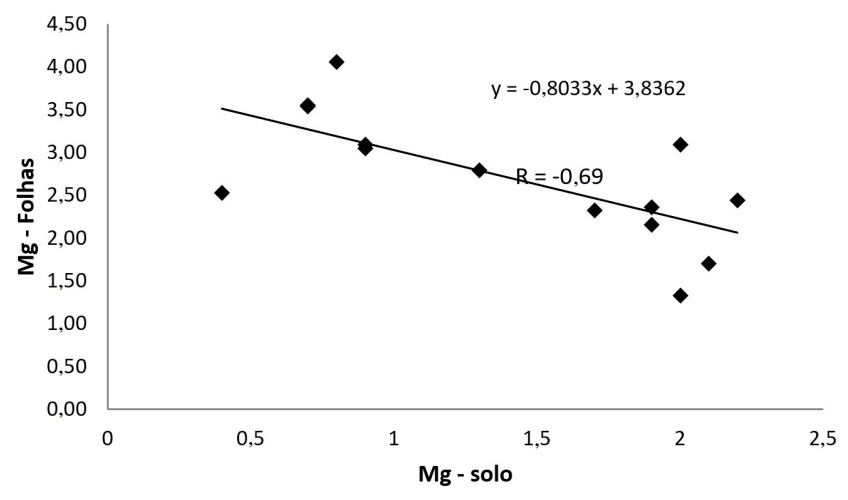

Figura 3. Correlação entre o teor de Mg no solo e nas folhas de couves do DF.

grande variabilidade de solos e amostras de plantas analisados, assim como a inibição competitiva do $\mathrm{Mg}$ pelo K (FAQUIN, 2001; PRADO, 2008), a sua aplicação em excesso e a elevada capacidade de absorção de nutrientes pelas brássicas (FILGUEIRA, 2008).

Os baixos valores para magnésio, boro e manganês encontrados nas folhas aventam para um manejo inadequado, empregado na correção e adubação dos solos cultivados com couve, o que é corroborado pelas respostas dos questionários sobre práticas de cultivo. Verificou-se, muitas vezes, que a adubação realizada pela maioria dos produtores de couve é baseada no empirismo, sem considerar os aspectos de fertilidade do solo e as necessidades das plantas, além da não utilização de fertilizantes que possuam fontes desses micronutrientes de maior solubilidade (Tabela 5).

Adicionalmente, mesmo que os teores de elementos químicos estejam altos no solo, a transferência destes para o interior das plantas, via absorção radicular, nem sempre é uma relação direta. Os elementos químicos, 
quando presentes na solução do solo, são passíveis de absorção pela planta e esse mecanismo pode se dar por difusão, fluxo de massa e interceptação radicular (MARSCHNER, 1995). Elementos como o cálcio e o magnésio são dependentes do fluxo de massa, que é governado pela presença de água no solo. Já o fósforo, que tem mobilidade limitada no solo devido às fortes reações de sorção nos argilominerais, é dependente da difusão. Uma vez no interior da planta, a dinâmica de redistribuição dos elementos químicos apresenta padrão bem distinto. Elementos como o nitrogênio, o potássio e o fósforo são muito móveis e participam da formação de novas estruturas vegetativas (ramos novos e folhas, por exemplo). Já o enxofre e o magnésio têm mobilidade intermediária, e o cálcio e o boro são bastante imóveis. A menor mobilidade de elementos no interior da planta faz com que sintomas de deficiência sejam sentidos nas partes

Tabela 3. Teores adequados de macro e micronutrientes em folhas de couve.

\begin{tabular}{|cccccc|}
\hline $\mathbf{N}$ & $\mathbf{P}$ & $\mathbf{K}$ & $\mathbf{C a}$ & $\mathbf{M g}$ & $\mathbf{S}$ \\
\hline \multicolumn{7}{c}{$\mathbf{g ~ k g}^{-1}$} \\
\hline $30-55$ & $3-7$ & $20-40$ & $15-25$ & $3-7$ & - \\
\hline $\mathbf{8}$ & $\mathbf{C u}$ & $\mathbf{F e}$ & $\mathbf{M n}$ & $\mathbf{M o}$ & $\mathbf{Z n}$ \\
\hline $30-100$ & $5-20$ & $60-300$ & $40-250$ & $0,4-0,8$ & $30-150$ \\
\hline
\end{tabular}

Fonte: Trani et al. (2015).

Tabela 4. Teores médios de minerais em folhas de couve do DF.

\begin{tabular}{|c|c|c|c|}
\hline $\mathbf{K}$ & Mg & $\mathbf{P}$ & $\mathbf{C a}$ \\
\hline \multicolumn{4}{|c|}{$\mathbf{g ~ k g}^{-1}$} \\
\hline $25,13 \pm 7,18$ & $2,73 \pm 0,8$ & $3,38 \pm 1,1$ & $16,03 \pm 2,38$ \\
\hline B & $\mathrm{Fe}$ & $\mathrm{Zn}$ & Mn \\
\hline
\end{tabular}

mais novas ou na porção superior da planta. A dinâmica dos elementos menores, os chamados micronutrientes, também segue esse caráter particular de mobilização no solo e translocação no interior das plantas (MALAVOLTA, 1997).

Deste modo, tal uso inadequado pode acarretar desequilíbrios nutricionais e perdas na produção e na qualidade da couve produzida nesses locais. Parte disso pode ser explicada pelas recomendações regionais defasadas - 30 anos de sua publicação (EMATER-DF, 1987) - para solos que mudaram sua condição química com o tempo. Os resultados obtidos nas análises de minerais nas folhas foram teores médios foliares de cálcio

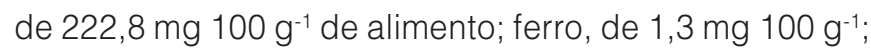
magnésio, de 37,6 mg $100 \mathrm{~g}^{-1}$, e zinco, de 0,6 mg $100 \mathrm{~g}^{-1}$, na couve produzida no DF. Este conteúdo atende a $28 \%$ das necessidades diárias de cálcio em crianças de 4 a 8 anos, suprindo também 13\% de ferro, 29\% de magnésio e 13\% de zinco, com base no consumo de $100 \mathrm{~g}$ de couve, segundo a recomendação de ingesta diária da USDA (OTTEN et al., 2006).

Na Tabela de Composição Nutricional da Unicamp (TACO), a quantidade de cálcio é de 130,9 mg $100 \mathrm{~g}^{-1}$ de alimento. Ferreira et al. (2001) quantificaram cálcio e magnésio em 208 alimentos consumidos na Região Sudeste do Brasil, e encontraram, em quatro amostras de couve, valores médios de cálcio de 400,1 mg 100 $\mathrm{g}^{-1}$ alimento e magnésio de 51,7 mg $100 \mathrm{~g}^{-1}$ alimento. Salvino (2014) quantificou cálcio em couve-manteiga Geórgia, cultivada na Região Nordeste do Brasil, e nas folhas verdes encontrou valores de cálcio de 277,2 mg $100 \mathrm{~g}^{-1}$, ferro de $0,7 \mathrm{mg} 100 \mathrm{~g}^{-1}$, zinco de 0,6 mg 100 $\mathrm{g}^{-1}$, magnésio de 66,17 mg $100 \mathrm{~g}^{-1}$ e manganês de 0,24 $\mathrm{mg} 100 \mathrm{~g}^{-1}$. Depois do processo de branqueamento e desidratação das folhas (base seca), os valores de cálcio aumentaram para 2.065,22 mg $100 \mathrm{~g}^{-1}$, ferro aumentou para

Tabela 5. Respostas ao questionário tratando da correção do solo e do uso de fertilizantes.

\begin{tabular}{|c|c|c|}
\hline Faz análise de solo & $\operatorname{Sim}(50 \%)$ & Não (50\%) \\
\hline Utiliza calcário anteriormente ao cultivo de couve? & $\operatorname{Sim}(100 \%)$ & Não $(0 \%)$ \\
\hline \multirow{6}{*}{ Quais são os fertilizantes utilizados na adubação de base? } & $4-14-8(35 \%)$ & \\
\hline & $4-30-16(25 \%)$ & \\
\hline & Composto orgânico (20\%); & \\
\hline & Cama de frango (10\%); & \\
\hline & Nitrato de cálcio (5\%); & \\
\hline & Sulfato de amônio (5\%). & \\
\hline \multirow{6}{*}{ Quais são os fertilizantes utilizados na adubação de cobertura? } & $20-0-20(55 \%)$ & \\
\hline & Composto orgânico (20\%); & \\
\hline & Ureia $(10 \%)$ & \\
\hline & $10-10-10(5 \%)$ & \\
\hline & Hortmax $^{\circledast}(5 \%)$; & \\
\hline & Não utiliza (5\%). & \\
\hline Faz adubação verde? & $\operatorname{Sim}(15 \%)$ & Não (85\%) \\
\hline
\end{tabular}


11,6 mg $100 \mathrm{~g}^{-1}$, zinco aumentou para 4,58 mg $100 \mathrm{~g}^{-1}$, magnésio aumentou para 665,56 mg $100 \mathrm{~g}^{-1}$ e manganês aumentou para 2,67 mg $100 \mathrm{~g}^{-1}$. Este aumento ocorreu por causa da concentração dos nutrientes em base seca. As folhas secas foram usadas para enriquecimento na fabricação de pães de fôrma. Segundo Buzinaro et al. (2006), o teor de cálcio em couve é 0,72 $\mathrm{mg} \mathrm{g}^{-1}$ do alimento, ou $72 \mathrm{mg} 100 \mathrm{~g}^{-1}$ do alimento, com absorção fracional de $49,3 \%$, enquanto que, no leite bovino integral, o teor de cálcio é de 1,25 mg g ${ }^{-1}$ do alimento, com absorção fracional de $32,1 \%$. Em termos práticos, para substituir uma porção de consumo de $240 \mathrm{~g}$ de leite bovino integral, são necessários 275,1 g de couve. A absorção fracional foi corrigida para a carga pelo uso da equação para o leite (absorção fracional = 0,889 a 0,0964 em carga) então ajustada para a razão de absorção do Ca do alimento-teste, em relação ao leite, testada para a mesma carga, indicando o índice absortivo. Os dados originais da absorção fracional são de Weaver et al. (1999). Na tabela da USDA (2016), a quantidade de cálcio encontrada em couve é de $150 \mathrm{mg}$ de $\mathrm{Ca} 100 \mathrm{~g}^{-1}$ de alimento. Em trabalho sobre composição nutricional de alimentos de Moçambique, Korkalo et al. (2011) encontraram valores de $135 \mathrm{mg}$ de Ca $100 \mathrm{~g}^{-1}$ de alimento, para couve. Comparando-se os resultados do presente trabalho, cujo valor médios foi de 222,8 mg $100 \mathrm{~g}^{-1}$, com dados da literatura observou-se que foi superior aos de outros países em até 170\% e inferior em $80 \%$ ao resultado encontrado por Salvino (2014), na Região Nordeste do Brasil. Assim, a variação entre os locais de produção foi reafirmada. Feiber e Caetano (2012) quantificaram o cálcio em couve preparada na forma de polpa, com $84 \%$ de água e $16 \%$ de couve, e encontraram 26,43 mg de Ca $100 \mathrm{~g}^{-1}$ de couve. O consumo de $100 \mathrm{~g}$ de couve atende, no consumo de um único alimento, a $28 \%$ das necessidades diárias de cálcio em crianças de 4 a 8 anos e 18,6\% da necessidade de ingesta diária de homens ou mulheres acima de 51 anos (OTTEN et al., 2006). O consumo de couve na forma de suco possibilita a inclusão de outros vegetais para compor alimentos com propriedades nutricionais adequadas à dieta de cada indivíduo e com sabor ajustado a cada paladar.

Oliveira-Calheiros et al. (2008) avaliaram a disponibilidade do ferro em dieta complementada com couve-manteiga, em uma dieta típica do Estado de São Paulo, que resultou no aumento da disponibilidade de ferro da refeição avaliada. Nas dietas contendo porções de couve crua os percentuais de disponibilidade de ferro foram maiores. Na dieta adicionada de couve crua, o teor de ferro foi de $10,39 \mathrm{mg} 100 \mathrm{~g}^{-1}$ e a disponibilidade de ferro, de 0,31\%. Na dieta adicionada de couve cozida, o teor de ferro foi de 5,36 mg $100 \mathrm{~g}^{-1}$ e a disponibilidade de ferro, de 0,27\%. A explicação é que a couve crua também apresentou maior concentração de ácido ascórbico, que é diminuído com a cocção.
A biodisponibilidade do ferro, ou seja, o quanto de ferro ingerido é absorvido e disponibilizado para o metabolismo, é de fundamental importância. O ferro contido nos alimentos de origem animal é mais bem absorvido (até 22\%) do que aquele de origem vegetal (1\% a 6\%). O fígado contém uma maior densidade de ferro e uma melhor biodisponibilidade do que, por exemplo, o leite e os seus derivados (GILLOOLY et al., 1983). Neste trabalho, os teores médios de ferro encontrados em folhas de couve foram de 1,3 mg de Fe $100 \mathrm{~g}^{-1}$ de couve, correspondendo às seguintes necessidades diárias de ingesta: crianças de 4 a 8 anos: 13\%; homens, a partir dos 31 anos de idade: 16,25\%; mulheres de 19 a 50 anos: $7,22 \%$ e mulheres a partir dos 51 anos: 16,25\% (OTTEN et al., 2006). Salvino (2014) quantificou minerais em couve-manteiga Geórgia, cultivada na Região Nordeste do Brasil, verificando que o teor de Mg nas folhas verdes cruas foi de 66,17 mg $100 \mathrm{~g}^{-1}$. Em um interessante estudo realizado na Polônia por Lisiewska et al. (2009), foi feita a quantificação de minerais em couve crua e foram encontrados teores de $\mathrm{Mg}$ (17,9 mg $\left.100 \mathrm{~g}^{-1}\right)$, Fe (0,96 mg $\left.100 \mathrm{~g}^{-1}\right)$, Zn (0,51 mg $\left.100 \mathrm{~g}^{-1}\right)$ e Ca (230,4 mg $\left.100 \mathrm{~g}^{-1}\right)$. Sikora e Bodziarczyk (2012) avaliaram outros componentes nutricionais e concluíram que, no consumo de folhas cruas, de modo geral, os compostos bioativos estão presentes

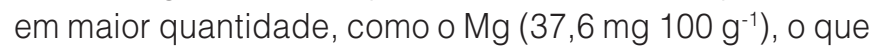
corresponde a $28,92 \%, 8,95 \%$ e $11,75 \%$ da necessidade diária de ingesta de crianças de 4 a 8 anos, homens a partir dos 31 anos de idade e mulheres a partir dos 31 anos, respectivamente (OTTEN et al., 2006).

Andrade et al. (2005) quantificaram o teor de zinco em couve através de espectroscopia de absorção atômica em chama e obtiveram 0,47 mg $100 \mathrm{~g}^{-1}$, com 100\% de extração com os extratores: solução de $\mathrm{CaCl}$ 1M; solução de ácido acético 0,1 M; solução de ácido acético 0,5 M/acetato de amônio 5\% $[\mathrm{pH}=5,0]$; solução de $\mathrm{NaOH} 0,1 \mathrm{M}$ e solução de $\mathrm{HCl} 0,5 \mathrm{M}$. Nesse trabalho, os teores médios de zinco encontrados em folhas de couve foram de 0,6 mg Zn $100 \mathrm{~g}^{-1}$ de couve, o que corresponde a $12 \%$ da necessidade diária de ingesta de crianças de 4 a 8 anos, 5,45\% da necessidade diária de ingesta de homens a partir dos 14 anos de idade e 7,5\% da necessidade diária de ingesta de mulheres a partir de 19 anos de idade (OTTEN et al., 2006). Couve é um alimento rico em cálcio, ferro, magnésio e zinco, e pode ser considerado fonte destes minerais, segundo a Anvisa (BRASIL, 2012), para cálcio e magnésio. As diferentes formas de preparo e a constante oferta de couve no mercado contribuem para o enriquecimento nutricional da dieta da população. Assim, a difusão do conhecimento da riqueza nutricional da couve deve ser estimulada, para aumentar a escolha consciente das pessoas no momento de suas compras para alimentação. 


\section{Conclusões}

Os dados obtidos com a realização deste trabalho permitem concluir que as folhas de couve produzidas no Distrito Federal são ricas em cálcio, ferro, magnésio e zinco. O conteúdo de fósforo e de potássio nos solos foi considerado alto. Por outro lado, foram constatados valores médios e baixos de magnésio. Para os teores foliares, o conteúdo de micronutrientes é considerado baixo e aventa para um manejo inadequado da adubação, fator corroborado pelas respostas dos questionários. Práticas de manejo que levem ao equilíbrio de nutrientes no solo refletem diretamente na interação solo-planta. Foi verificada correlação negativa para teores de magnésio no solo e na folha, com $R=-0,69$. Para os outros minerais analisados não se verificou correlação significativa. Mais estudos são necessários para recomendações regionais atualizadas de adubação e correção dos solos, que poderiam auxiliar agricultores e técnicos, refletindo diretamente na obtenção de teores mais equilibrados de minerais para as plantas e para a dieta humana.

\section{Agradecimentos}

Agradecemos pelo apoio de pessoas e pela infraestrutura da Embrapa Hortaliças; pelo apoio financeiro da FAP-DF, que disponibilizou recursos para este projeto ("Caracterização e identificação de compostos bioativos de couves produzidas e consumidas no Distrito Federal" do Edital 03 de 2015, número 0193.00101/2015), e ao CNPq, pela Bolsa de Iniciação Científica. Também, de modo especial, pela acolhida e pela doação das amostras de couve dos produtores de couve do DF que foram usadas nas análises. Os produtores foram informados dos resultados das análises feitas com as amostras doadas.

\section{Referências}

ANDRADE, É. C. B.; TEODORO, A. J.; TAKASE, I. Determinação dos teores de Zinco em diferentes extratos de hortaliças dos tipos A e B. Food Science and Technology, v. 25, n. 2, p. 265-270, 2005. http://dx.doi.org/10.1590/S0101-20612005000200014.

BRAGA, D. F.; ALVES S. V.; MEDEIROS V. F; MENDONÇA J. D.; FERNANDES L. B. Metodologias mais utilizadas para análise de fósforo no solo. Enciclopédia Biosfera, v. 6, n. 11, p. 1-11, 2010.

BRASIL. Ministério da Saúde. Política Nacional de Alimentação e Nutrição: conquistas e avanços. Brasília, 2002.

BRASIL. Ministério da Saúde. Agência Nacional de Vigilância Sanitária. Resolução n 54, de 12 de novembro de 2012. Regulamento técnico sobre informação nutricional complementar. Diário Oficial [da] República Federativa do Brasil, Brasília, DF, 21 nov. 2012. Seção 1, p. 15.

BUENO, A. L.; CZEPIELEWSKI, M. A. A importância do consumo dietético de cálcio e vitamina $D$ no crescimento. Jornal de
Pediatria, v. 84, n. 5, p. 386-394, 2008. http://dx.doi.org/10.2223/ JPED.1816. PMid:18923788.

BUZINARO, E. F.; ALMEIDA, R. N. A.; MAZETO, G. M. F. S. Biodisponibilidade do cálcio dietético. Arquivos Brasileiros de Endocrinologia \& Metabologia, v. 50, n. 5, p. 852-861, 2006. http://dx.doi.org/10.1590/S0004-27302006000500005.

EMPRESA DE ASSISTÊNCIA TÉCNICA E EXTENSÃO RURAL DO DISTRITO FEDERAL - EMATER-DF. Recomendações para o uso de corretivos, matéria orgânica e fertilizantes para hortaliças no Distrito Federal: $1^{a}$ aproximação. Brasília, 1987. 50 p

FADIGAS, J. C.; SANTOS, A. M. P.; JESUS, R. M.; LIMA, D. C.; FRAGOSO, W. D.; DAVID, J. M.; FERREIRA, S. L. C. Use of multivariate analysis techniques for the characterization of analytical results for the determination of the mineral composition of kale. Microchemical Journal, v. 96, n. 2, p. 352-356, 2010. http://dx.doi.org/10.1016/j.microc.2010.06.006.

FAQUIN, V. Nutrição mineral de plantas. Lavras: Universidade Federal de Lavras, 2001. 182 p.

FEIBER, L. T.; CAETANO, R. Estudo da composição centesimal e teores de Cálcio em polpas de couve (Brassica oleraceae var. Acephala). Alimentos e Nutrição, v. 23, n. 1, p. 141-145, 2012. FERREIRA, K. S.; GOMES, J. C.; BELLATO, C. R. Concentrações de cálcio e de magnésio em alguns alimentos consumidos no Brasil. Brazilian Journal of Food Technology, v. 4, p. 123-130, 2001.

FILGUEIRA, F. A. R. Novo manual de olericultura: agrotecnologia moderna na produção e comercialização de hortaliças. Viçosa: UFV, 2008. 421 p.

GILLOOLY, M.; BOTHWELL, T. H.; TORRANCE, J. D.; MACPHAIL, A. P.; DERMAN, D. P.; BEZWODA, W. M.; MILLS, W.; CHARLTON, R. W.; MAYET, F. The effect of organic acids, phytates and polyphenols on the absorption of iron from vegetables. British Journal of Nutrition, v. 49, n. 3, p. 331-342, 1983. http://dx. doi. org/10.1079/BJN19830042. PMid:6860621.

KORKALO, L.; HAUTA-ALUS, H.; MUTANEN, M. Food composition tables for Mozambique. Finland: Department of Food and Environmental Sciences, University of Helsinki, 2011. 55 p. Disponível em: <http://www.helsinki.fi/food-and-environment/ research/groups/Food_composition_tables_for_Mozambique. pdf>. Acesso em: 19 jun. 2017.

LISIEWSKA, Z.; GEBCZYNSKI, P.; BERNAS, E.; KMIECIK, W. Retention of mineral constituents in frozen leafy vegetables prepared for consumption. Journal of Food Composition and Analysis, v. 22, n. 3, p. 218-223, 2009. http://dx. doi.org/10.1016/j. jfca.2008.11.015.

LUENGO, R. F. A.; PARMAGNANI, R. M.; PARENTE, M. R.; LIMA, M. F. B. F. Tabela de composição nutricional de hortaliças. Brasília: Embrapa Hortaliças, 2000. (Documentos 26).

MALAVOLTA, E. Avaliação do estado nutricional das plantas: princípios e aplicações. In: MALAVOLTA, E.; VITTI, G. C.; OLIVEIRA, 
Determinação de minerais no solo e análise de folhas de couve produzida em Brasília

Luengo, R. F. A. et al.

S. A. Avaliação do estado nutricional de plantas: princípios e aplicações. 2. ed. ver. e atual. Piracicaba: Potafos, 1997.

MARSCHNER, $H$. Mineral nutrition of higher plants. 2nd ed. London: Academic Press, 1995. 889 p.

MARTINEZ, H. E. P.; CARVALHO, J. G.; SOUZA, R. B. Diagnose foliar. In: RIBEIRO, A. C.; GUIMARÃES, P. T. G.; ALVAREZ V. V. H. Recomendações para o uso de corretivos e fertilizantes em Minas Gerais: $5^{a}$ aproximação. Viçosa: Comissão de Fertilidade do Solo do Estado de Minas Gerais, 1999. p. 143-168.

MENDES, R. O impacto dos efeitos da ocupação sobre a saúde de trabalhadores: I. morbidade. Revista de Saúde Pública, v. 22, n. 4, p. 311-326, 1988. http://dx.doi.org/10.1590/S003489101988000400007

OLIVEIRA-CALHEIROS, K.; CANNIATTI-BRAZACA, S. G.; SOUZA, M. C. Evaluation of iron availability at diet complemented with cabbage. Alimentos e Nutrição, v. 19, n. 1, p. 37-42, 2008.

OTTEN, J. J.; HELLWIG, J. P.; MEYERS, L. D. (Ed.). Dietary reference intakes: the essential guide to nutrient requirements. Washington: The National Academies Press, 2006. 1329 p. Disponível em: <http://www.nal.usda.gov/fnic/DRI/Essential_Guide/ DRIEssentialGuideNutReq.pdf>. Acesso em: 21 jun. 2017.

PRADO, R. M. Nutrição de plantas. São Paulo: Editora Unesp, 2008. 407 p.

PRIMAVESI, A. Manejo ecológico do solo: a agricultura em regiões tropicais. São Paulo: Nobel, 2002. 555 p.

RAIJ, B.; FEITOSA, C. T.; DA SILVA, N. M. Comparação de quatro extratores de fósforo de solos. Bragantia, v. 43, n. 1, p. 17-29, 1984. http://dx.doi.org/10.1590/S0006-87051984000100003.

SALGUEIRO, M. J.; ZUBILLAGA, M. B.; LYSIONEK, A. E.; CARO, R. A.; WEILL, R.; BOCCIO, J. R. The role of zinc in the growth and development of children. Nutrition, v. 18, n. 6, p. 510-519, 2002. http://dx. doi.org/10.1016/S0899-9007(01)00812-7. PMid:12044825.

SALVINO, E. M. Avaliação química e nutricional de couve (Brassica oleraceae var. Acephala) e aplicação em formulações de pães de forma. 2014. 68 f. Tese (Doutorado)-Universidade Federal da Paraíba, João Pessoa, 2014.
SIKORA, E.; BODZIARCZYK, I. Composition and antioxidant activity of kale (Brassica oleracea L. var. acephala) raw and cooked. Acta Scientiarum Polonorum, v. 11, n. 3, p. 239-248, 2012. PMid:22744944.

SILVA, F. C. Manual de análises químicas de solos, plantas e fertilizantes. 2. ed. rev. ampl. Brasília: Embrapa Informação Tecnológica, 2009. 627 p.

SOARES, J. L. P. Mapeamento da produção de hortaliças do Distrito Federal. 2013. 57 f. Monografia (Bacharelado em Gestão do Agronegócio)-Universidade de Brasília, Planaltina, 2013.

TRANI, P. E.; TIVELLI, S. W.; BLAT, S. F.; PRELA-PANTANO, A.; TEIXEIRA, É. P.; ARAÚJO, H. S.; FELTRAN, J. C.; PASSOS, F. A.; FIGUEIREDO, G. J. B.; NOVO, M. C. S. S. Couve de folha: do plantio à pós-colheita. Campinas: Instituto Agronômico, 2015. 36 p

UNITED STATES DEPARTMENT OF AGRICULTURE - USDA. National Nutrient Database for Standard Reference Release 28. Basic report: 11233, Kale, raw. Washington, 2016. Disponível em: <https://ndb.nal.usda.gov/ndb/foods/show/2983>. Acesso em: 3 maio 2017.

UNIVERSIDADE ESTADUAL DE CAMPINAS - UNICAMP. Núcleo de Estudos e Pesquisas em Alimentação - NEPA. Tabela Brasileira de composição de alimentos. T113 versão II. Campinas: NEPAUNICAMP, 2006. 105 p.

UNIVERSIDADE FEDERAL DE SÃO PAULO - UNIFESP. Escola Paulista de Medicina - EPM. TABNUT: Tabela de composição química dos alimentos. São Paulo, 2016. Disponível em: <http:// tabnut.dis.epm.br/>. Acesso em: 24 jul. 2017.

VAN DER SLUIS, I. M.; MUINCK KEIZER-SCHRAMA, S. M. P. F. Osteoporosis in childhood: bone density in children in health and disease. Journal of Pediatric Endocrinology \& Metabolism, v. 14, n. 7, p. 817-832, 2001. http://dx.doi.org/10.1515/ JPEM.2001.14.7.817. PMid:11515724.

WEAVER, C. M.; PROULX, W. R.; HEANEY, R. Choices for achieving adequate dietary calcium with a vegetarian diet. The American Journal of Clinical Nutrition, v. 70, n. 3, p. 543S-548S, 1999. Suplemento. http://dx.doi.org/10.1093/ajcn/70.3.543s. PMid:10479229 